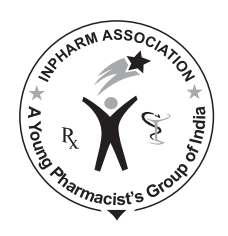

\title{
JIP
}

\section{Antiurolithiatic Effects of Solanum xanthocarpum Fruit Extract on Ethylene-Glycol-Induced Nephrolithiasis in Rats}

\author{
Patel PK, Patel MA, Saralai MG, Gandhi TR' \\ Department of Pharmacology, C. K. Pithawalla Institute of Pharmaceutical Science and Research, \\ Surat-Dumas Road, Surat, Gujarat, ${ }^{1}$ Department of Pharmacology, Anand Pharmacy College, Anand, \\ Gujarat, India
}

Address for correspondence: Prof. Paras K. Patel; E-mail: paras.pharm@gmail.com

\begin{abstract}
This study was designed to evaluate the effects of Solanum xanthocarpum fruit extract in ethylene-glycolinduced urolithiasis in the male Wistar rats. Nephrolithiasis was induced in male Wistar rats by adding ethylene glycol $(0.75 \%)$ in drinking water for 28 days. Animals were divided into six groups, each containing six viz. Vehicle control, model control, S. xanthocarpum methanol extract in different doses of 100,200 , and $400 \mathrm{mg} /$ $\mathrm{kg}$ p.o., Cystone $(750 \mathrm{mg} / \mathrm{kg}$, p.o.) served as a standard. Hyperoxaluria as well as an increase in the excretion of calcium, phosphate, uric acid and decrease in citrate and magnesium in urine, impairment of renal function and oxidative imbalance in kidney were observed in the calculi-induced group. Treatment with $S$. xanthocarpum decreases hyperoxaluria, calcium, and uric acid, improves renal function, and also produces antioxidant effects. Crystalluria was characterized by excretion calcium oxalate $(\mathrm{CaOX})$ crystals, which were enormous in the lithogenic group but smaller in the drug-treated group. The histology showed that the calculi-induced group had a large deposition of $\mathrm{CaOX}$ crystals in kidney while the treated group had trivial and fewer deposits. The result indicates the antiurolithiatic activity of $S$. xanthocarpum mediated possibly by $\mathrm{CaOX}$ crystal inhibition, diuretic, antioxidant and maintaining balance between stone promoter and inhibitor constituents, and this study rationalized its medicinal use in urolithiasis.
\end{abstract}

Key words: Calcium oxalate, ethylene glycol, Solanum xanthocarpum, urolithiasis

\section{INTRODUCTION}

Urolithiasis has afflicted humankind since antiquity and can persist with serious consequences throughout a patient's lifetimes. The management of urolithiasis

\begin{tabular}{|l|l|}
\hline \multicolumn{2}{|c|}{ Access this article online } \\
\hline Quick Response Code: & \\
\hline & Website: \\
\hline & www.jyoungpharm.in \\
& DOI: \\
\hline
\end{tabular}

remains a problem. Etiopathogenesis of this disorder is yet uncertain, and recurrence cannot be prevented by surgery or lithotripsy. A large number of plants have been used in India since ancient times, which claim the efficient cure of urinary stone. ${ }^{[1]}$ One of the such reputed plants is Solanum xanthocarpum Schrad. and Wendl. (Family: Solanaceae), commonly known as Yellow Berried Nightshade (syn—kantakari), found throughout India, mostly in dry places like a weed on roadsides and wastelands. ${ }^{[2]}$ The fruits are glabrous, globular berries, green, and white strips when young but yellow when mature. ${ }^{[3]}$ The fruits are known for several medicinal uses such as anthelmintic, antipyretic, laxative, anti-inflammatory, antiasthmatic, diuretic, urinary 
stone, and aphrodisiac activities. ${ }^{[4,5]}$ The stem, flowers, and fruits are prescribed for relief in burning sensation in the feet accompanied by vesicular eruptions. ${ }^{\left[{ }^{[6]}\right.}$ The fruit paste is applied externally to the affected area for treating pimples and swellings. ${ }^{[7]}$ Chauhan $e t$ al. ${ }^{[8]}$ reported that people in Muzaffarnagar (India) used S. xanthocarpum for the treatment of urinary infcetions and kidney stones. Many ancient literatures on Ayurveda describe the traditional use of $S$. xanthocarpum in the treatment of urolithiasis. ${ }^{[3,4,-11]}$ The fruits are reported to contain several steroidal glycol-alkaloids such as solasodine, solanacarpine, solanacarpidine, solancarpine, solasonine, and solamargine. ${ }^{[12]}$ Other constituents such as caffeic acid, coumarins such as aesculetin and aesculin, steroid carpesterol, diosgenin, campesterol, daucosterol, triterpenes such as cycloartanol and cycloartenol, and saponins were reported from the fruits. ${ }^{[10,13]}$ The antispasmodic, antitumor, cardiotonic, hypotensive, antianaphylactic, cytotoxic, and antidiabetic activities were also reported. ${ }^{[12,14,15]}$ Therefore, this study has been planned to establish the scientific validity of the antiurolithiatic activity of the $S$. xanthocarpum fruit methanol extract (SXME) using ethylene-glycol-induced urolithiasis in the male albino Wistar rats.

\section{MATERIALS AND METHODS}

\section{Plant material and preparation of the extract}

S. xanthocarpum fruits were collected from Surat, Gujarat, during the month of April-May 2008; it was identified and authenticated by the Botanist, Veer Narmad South Gujarat University, Surat, India. A voucher specimen of the plant was deposited in the herbarium (PKP/10102008/01). The fruits were a shade dried and ground to coarse powder. The powder packed in a Soxhlet's column and extracted with methanol at $70-75^{\circ} \mathrm{C}$ for $24 \mathrm{~h}$. The extraction procedure repeated, pooled extract was evaporated at $45^{\circ} \mathrm{C}$, under vacuum and stored in an airtight container. The yield of the extract $13.66 \% \mathrm{w} / \mathrm{w}$ was reddish-brown dry powder. The powder was qualitatively analyzed for the presence of various phytochemical constituents. ${ }^{[3]}$

\section{Determination of methanol in the extract}

Extraction was made using methanol, which is a class 2 residual solvent according to United States Pharmacopoeia (USP). Therefore, the methanol content was determined according to the USP using gas chromatography (Shimandzu Gas ChromatographGC-2014 with Headspace Auto sampler HT) and a minimum permeable limit of the methanol content is $<3000 \mathrm{ppm} .{ }^{[16]}$

\section{Animal}

Adult albino Wistar rats (male for antiurolithiatic study) and female (for acute oral toxicity study) weighing between 200-250 g housed in standard conditions of temperature $\left(22 \pm 2^{\circ} \mathrm{C}\right)$, relative humidity $(55 \pm 5 \%)$, and light (12 h light-dark cycles) were used. They have been fed with standard pellet diet and water ad libitum. The study protocol was approved by the Institutional Animal Ethics Committee according to the regulation of Committee for the Purpose of Control and Supervision of Experiments on Animals. The experiment was conducted in accordance with accepted standard guidelines for the care and use of animals in scientific research. ${ }^{[17]}$

\section{Acute toxicity testing}

The acute oral toxicity study was carried out in female rats as per the guidelines set by the Organization for Economic Cooperation and Development (OECD) number 425 (up and down procedure) and found out maximum tolerable dose. ${ }^{[18]}$

\section{Antiurolithiatic activity}

An ethylene glycol model was used to induce urolithiasis. ${ }^{[19,20]}$ Thirty-six animals were randomly divided into six groups as group I, II, III, IV, V, and VI containing six in each. Group I served as a vehicle control and maintained on regular rat food and drinking water ad libitum. All remaining groups received calculi-inducing treatment for 28 days, comprised of $0.75 \% \mathrm{v} / \mathrm{v}$ ethylene glycol in drinking water ad libitum. Group II received ethylene glycol only served as a model control for 28 days. Group III was administered Cystone $750 \mathrm{mg} / \mathrm{kg}$ body weight (The Himalaya Drug Company, India.) from 1 st day to 28th day of calculi induction and served as a standard. Groups IV, V, and VI served as treatment groups, received to extract at doses of 100, 200, and $400 \mathrm{mg} / \mathrm{kg}$ body weight, respectively, from $1 \mathrm{st}$ day to 28th day of calculi induction. Extract and standard drugs were dissolved in distilled water and given once daily by the oral route using the gastric tube.

\section{Collection and analysis of the urine}

All animals were kept in individual metabolic cages, and $24 \mathrm{~h}$ urine samples were collected on $28^{\text {th }}$ day of calculi induction treatment. Following volume, $\mathrm{pH}$, and crystalluria determination, urine was acidified with a drop of concentrated $\mathrm{HCl}$ and stored at $-20^{\circ} \mathrm{C}$ for determination of various parameters. Urine was analyzed for calcium, ${ }^{[21]}$ oxalate, ${ }^{[22]}$ magnesium, ${ }^{[23]}$ phosphate, ${ }^{[24]}$ uric acid, ${ }^{[25]}$ and citrate. ${ }^{[26]}$ 


\section{Serum analysis}

After the experimental period, blood was collected from retro-orbital under light ether anesthesia, and animals were killed by the cervical decapitation. ${ }^{[27]}$ Serum was separated by centrifugation at $10,000 \times g$ for $10 \mathrm{~min}$ and analyzed for the creatinine, uric acid, urea, and blood urea nitrogen (BUN) using diagnostic kits (Span Diagnostics Ltd., India).

\section{Kidney histopathology and homogenate analysis}

The abdomen was incised and opened, then to remove both kidneys from each animal; isolated kidneys were cleaned off extraneous tissue, after that weighed and rinsed with ice-cold normal saline. The left kidney was fixed with $10 \% \mathrm{v} / \mathrm{v}$ neutral formalin and processed through graded alcohol series and xylene, embedded in paraffin, sectioned at $5 \mu \mathrm{m}$, and stained with the hematoxylin and eosin for histopathological examination under a light microscope.

The right kidney was finely chopped and 20\% homogenate prepared in Tris-HCl buffer ( $\mathrm{pH}$ 7.4). Total kidney homogenate was used for assaying tissue calcium and oxalate, ${ }^{[22]}$ malondialdehyde (MDA), superoxide dismutase (SOD), catalase, and reduced glutathione (GSH) measured using commercially available kits (Span Diagnostics Ltd., India).

\section{Statistical analysis}

The results were presented, as mean $\pm \mathrm{SD}$. Difference among data was statistically analyzed using ANOVA followed by Dunnett's test to find out the level of significance using Sigmaplot software (Systat Software Inc., USA, Version: 10.0.1). A $P<0.05$ was considered as statically significant.

\section{RESULTS}

Qualitative phytochemicals analysis of SXME powder showed the presence of alkaloids, saponins, glycosides, tannins, carbohydrates, flavonoids, phenolic compounds, and steroids. The methanol content in the extract was found to be $1575.03 \mathrm{ppm}$, which was less than the permeable limit of USP.

From the acute oral toxicity study, the cut-off dose was found to be $2000 \mathrm{mg} / \mathrm{kg}$ body weight for the extract. Hence, experimental doses were taken as 100, 200, and $400 \mathrm{mg} / \mathrm{kg}$ of body weight for the evaluation.

Crystals were absent in urine of vehicle control animals, while in the lithogenic treatment-induced group, crystals were more numbers with larger sizes. Treatment with SXME powder clearly reduced the crystal number as well as the crystal size [Figure 1].

The $24 \mathrm{~h}$ urine volume was high in the model control group $(P<0.001)$ compared to those of the vehicle control animals. In the SXME-treated group, the urine output was significantly higher than that of calculi-induced rats. Lithogenic treatment also changed urine $\mathrm{pH}$ in the untreated group and treated groups, but it was not to a significant extent at various doses of SXME powder [Table 1].

There was significant increased urine excretion of calcium, oxalate, uric acid, and phosphate $(P<0.001)$ in the calculiinduced group compared to the vehicle control group. However, co-treatment with SXME powder significantly prevented these changes in the urinary calcium, oxalate, uric acid, and phosphate excretion dose dependently in the groups III-VI [Table 1].

Urinary excretion of magnesium and citrate was decreased significantly $(P<0.001)$ in the stone forming group compared to the vehicle control group. Supplementation with the SXME powder substantially prevented these changes and restored it near to normal values [Table 1].

As compared to a vehicle control group, the stone inducing regimen caused a significant impairment of renal functions of the untreated group shown by a significant high level $(P<0.001)$ of creatinine, uric acid, urea, and BUN in serum. These were dose dependently inhibited in the animals receiving a simultaneous treatment with SXME powder [Table 1].

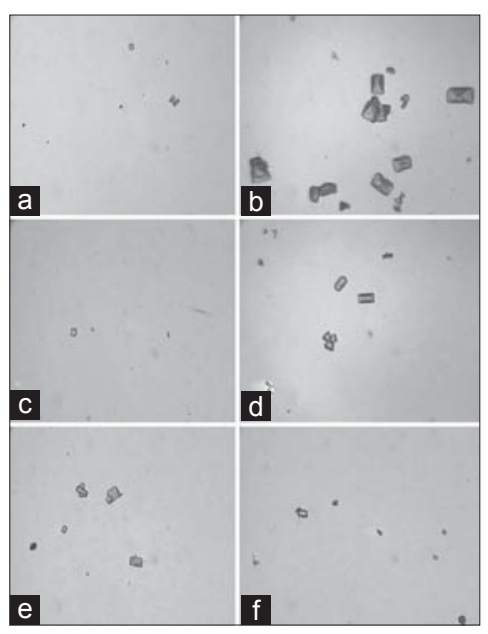

Figure 1: The CaOX crystals viewed using a light microscope in urine from (a) vehicle control group, (b) calculi induce group, (c) Cystone (750 mg/kg) and the group receiving the Solanum xanthocarpum fruit extract (d) $100 \mathrm{mg} / \mathrm{kg}$, (e) $200 \mathrm{mg} / \mathrm{kg}$, and (f) $400 \mathrm{mg} / \mathrm{kg}$ (magnification $450 \times$ for all images) 
The kidney weight was significantly $(P<0.01)$ increased in the lithogenic group compared to the vehicle control group. When compare to calculi induced group, the SXME treated animals showed significant decrease in kidney weight, reduced renal content of stone forming constituents, and the effect was dose dependent [Table 2]. The crystalline components such as calcium and oxalate were significantly increased in stone forming rats compared to the control $(P<0.001)$ [Table 2].

Stone inducing treatment enhanced the MDA $(P<0.001)$ content and decreased the GSH $(P<0.001)$ level and activities of antioxidant enzymes, including SOD $(P<0.001)$ and catalase $(P<0.001)$ in the kidney of untreated rats compared to control animals. A co-administration with SXME powder protected against the oxidative changes induced by lithogenic treatment in a dose-dependent manner [Table 2].

Histopathological examination of kidney revealed the normal glomeruli and tubular region with the absence of calcium oxalate $(\mathrm{CaOX})$ crystals in vehicle control animals [Figure $2 \mathrm{a}$ and $2 \mathrm{~b}$ ]. While in the stone forming group, severe glomeruli damage, RBCs deposition, which leads to hematuria, numerous and large size $\mathrm{CaOX}$ crystal deposition in the renal tubule and dilation of the proximal tubules with interstitial inflammation were observed in the renal tissue [Figure $2 \mathrm{c}$ and $2 \mathrm{~d}$ ]. Treatment with CYSTONE and SXME decreased glomeruli damage, less RBCs accumulation, fewer numbers and smaller size $\mathrm{CaOX}$ crystal deposition with fragmentation in a dose dependent manner in comparison to the calculi-induced group [Figure 2e and 2f, Figure 3].

\section{DISCUSSION}

Stone formation in the ethylene glycol fed is caused by hyperoxaluria, which causes increased renal retention and excretion of oxalate. ${ }^{[19,20]}$ Deposition of renal $\mathrm{CaOX}$ by the ethylene glycol $0.75 \% \mathrm{v} / \mathrm{v}$ for 28 days in the rat model is frequently used to mimic the urinary stone formation in humans. ${ }^{[19]}$

Treatment with SXME causes diuresis by increasing the urinary volume that decreases supersaturation process, which is one of the favorable requisition factors for stone formation by crystallization. Similar results are also observed when lupeol is used as an antilithic agent. ${ }^{[28,29]}$ Acidic urine is usually found in humans with idiopathic renal $\mathrm{CaOX}$ stone formation, whereas chronic hyperoxaluric rats have alkaline urine. ${ }^{[30]}$ The mechanism of alkaline urine production after ethylene glycol treatment and its possible correlation with nephrolithiasis in this rat model remains unclear and needs further studies. Formation of kidney stone is a complex process that results from a success of several physicochemical events, including supersaturation, nucleation growth-aggregation, and retention within the renal tubules. ${ }^{[3]}$ This may be important as large particles have a greater chance of being trapped within the renal tubules, whereas small particles can be flushed easily from the kidney. Crystalluria could occur similarly in both healthy and stone-forming subjects, but the latter might tend to excrete massive and aggregated particles. ${ }^{[3]}$ The analysis of crystalluria showed that rats of the lithogenic group excreted more and big size $\mathrm{CaOX}$ crystals than the drug-treated groups. These effects may be due to increased urine volume that decreases supersaturation, also inhibit

Table 1: Effects of the methanol extract of Solanum xanthocarpum fruits on urine, and serum parameters in urolithiasis-induced rats

\begin{tabular}{|c|c|c|c|c|c|c|}
\hline \multirow[t]{2}{*}{ Parameters } & \multirow[t]{2}{*}{ Control } & \multirow{2}{*}{$\begin{array}{l}\text { Model control } \\
\text { (EG only) }\end{array}$} & \multirow[t]{2}{*}{ EG + Cystone } & \multicolumn{3}{|c|}{ EG + Solanum xanthocarpum } \\
\hline & & & & $100 \mathrm{mg} / \mathrm{kg}$ & $200 \mathrm{mg} / \mathrm{kg}$ & $400 \mathrm{mg} / \mathrm{kg}$ \\
\hline \multicolumn{7}{|l|}{ Urine (mg/24 h) } \\
\hline Urine volume & $10.76 \pm 1.08$ & $15.56 \pm 3.33^{\mathrm{a} *}$ & $24.18 \pm 1.10^{\mathrm{a} * \mathrm{~b} *}$ & $19.86 \pm 1.66^{\mathrm{a}^{* \mathrm{~b}^{\wedge}}}$ & $21.80 \pm 1.91^{\mathrm{a} * \mathrm{~b} *}$ & $22.36 \pm 1.49^{\mathrm{a} *, \mathrm{~b} *}$ \\
\hline $\mathrm{pH}$ & $6.41 \pm 0.58$ & $7.55 \pm 0.56$ & $6.65 \pm 0.71$ & $6.68 \pm 0.95$ & $6.88 \pm 0.53$ & $6.70 \pm 0.53$ \\
\hline Calcium & $4.74 \pm 0.56$ & $7.91 \pm 0.53^{\mathrm{a} *}$ & $4.72 \pm 0.44^{\mathrm{b} *}$ & $5.87 \pm 0.46^{\mathrm{a}^{\wedge}, \mathrm{b} *}$ & $5.25 \pm 0.56^{\mathrm{b} *}$ & $4.98 \pm 0.61^{\mathrm{b} *}$ \\
\hline Oxalate & $3.25 \pm 0.26$ & $7.84 \pm 0.41^{\mathrm{a} *}$ & $3.87 \pm 0.61^{\mathrm{b} *}$ & $6.47 \pm 0.78^{\mathrm{a} *, \mathrm{~b} *}$ & $5.78 \pm 0.63^{\mathrm{a} * \mathrm{~b} *}$ & $4.84 \pm 0.34^{\mathrm{a} * \mathrm{~b} *}$ \\
\hline Uric acid & $1.43 \pm 0.29$ & $3.58 \pm 0.36^{\mathrm{a} *}$ & $1.81 \pm 0.44^{\mathrm{b} *}$ & $2.59 \pm 0.49^{\mathrm{a} *, \mathrm{~b} *}$ & $2.06 \pm 0.46^{\mathrm{a} \#, \mathrm{~b} *}$ & $1.90 \pm 0.29^{\mathrm{b} *}$ \\
\hline Phosphate & $4.83 \pm 0.36$ & $7.39 \pm 0.56^{\mathrm{a} *}$ & $5.58 \pm 0.53^{\mathrm{b} *}$ & $6.78 \pm 0.51^{a *}$ & $6.14 \pm 0.63^{\mathrm{a} * \mathrm{~b} \#}$ & $5.73 \pm 0.56^{\mathrm{a} \#, \mathrm{~b} *}$ \\
\hline Citrate & $48.53 \pm 5.46$ & $30.77 \pm 1.78^{a *}$ & $49.82 \pm 2.62^{\mathrm{b} *}$ & $38.98 \pm 2.37^{\mathrm{a}, \mathrm{b} \#}$ & $43.53 \pm 4.62^{\mathrm{b} *}$ & $47.24 \pm 3.06^{\mathrm{b} *}$ \\
\hline Magnesium & $2.66 \pm 0.36$ & $1.36 \pm 0.31^{\mathrm{a} *}$ & $2.59 \pm 0.32^{\mathrm{b} *}$ & $1.74 \pm 0.29^{\mathrm{a} *}$ & $1.90 \pm 0.41^{\mathrm{a}^{\wedge}, \mathrm{b \#}}$ & $2.12 \pm 0.24^{\mathrm{a} \#, \mathrm{~b}^{\wedge}}$ \\
\hline \multicolumn{7}{|l|}{ Serum $(\mathrm{mg} / \mathrm{dl})$} \\
\hline Creatinine & $0.72 \pm 0.07$ & $2.27 \pm 0.49^{a *}$ & $0.73 \pm 0.14^{\mathrm{b} *}$ & $1.47 \pm 0.26^{\mathrm{a} * \mathrm{~b} *}$ & $0.88 \pm 0.04^{\mathrm{b} *}$ & $0.81 \pm 0.09^{\mathrm{b} *}$ \\
\hline Uric acid & $3.14 \pm 0.44$ & $5.05 \pm 0.80^{\mathrm{a} *}$ & $3.37 \pm 0.61^{\mathrm{b} *}$ & $4.48 \pm 0.41^{\mathrm{a}^{\wedge}}$ & $4.06 \pm 0.63^{\mathrm{a} \# \mathrm{~b} \#}$ & $3.91 \pm 0.41^{\mathrm{a} *, \mathrm{~b}^{\wedge}}$ \\
\hline Urea & $16.22 \pm 1.73$ & $27.02 \pm 3.42^{\mathrm{a} *}$ & $17.50 \pm 3.40^{\mathrm{b} *}$ & $22.14 \pm 2.76^{\mathrm{a}^{\wedge} \mathrm{b} \#}$ & $20.47 \pm 2.96^{b^{\wedge}}$ & $19.36 \pm 3.55^{\mathrm{b} *}$ \\
\hline BUN & $35.22 \pm 8.57$ & $62.87 \pm 7.81^{\mathrm{a} *}$ & $39.05 \pm 5.31^{b *}$ & $52.63 \pm 5.21^{\mathrm{a} * \mathrm{~b} \#}$ & $47.36 \pm 4.55^{\mathrm{a}^{\wedge} \mathrm{b} *}$ & $44.91 \pm 4.94^{\mathrm{a} \#, \mathrm{~b} *}$ \\
\hline
\end{tabular}

Values are expressed as mean \pm SD, 6 animals in each group. EG: ethylene glycol. Comparisons are made: ${ }^{a}$ with control, ${ }^{b}$ with model control (EG only). One way ANOVA followed by Dunnett Test. Symbols represent statistical significance: ${ }^{\sharp} P<0.05, \wedge P<0.01,{ }^{*} P<0.001$, BUN: Blood urea nitrogen 
Patel, et al:: Antiurolithiatic activity of S. xanthocarpum

Table 2: Effects of the methanol extract of Solanum xanthocarpum fruits on kidney parameters in urolithiasisinduced rats

\begin{tabular}{|c|c|c|c|c|c|c|}
\hline \multirow[t]{2}{*}{ Parameters } & \multirow[t]{2}{*}{ Control } & \multirow{2}{*}{$\begin{array}{l}\text { Model control } \\
\text { (EG only) }\end{array}$} & \multirow[t]{2}{*}{ EG + Cystone } & \multicolumn{3}{|c|}{ EG + Solanum xanthocarpum } \\
\hline & & & & $100 \mathrm{mg} / \mathrm{kg}$ & $200 \mathrm{mg} / \mathrm{kg}$ & $400 \mathrm{mg} / \mathrm{kg}$ \\
\hline Kidney weight (g) & $1.39 \pm 0.36$ & $2.31 \pm 0.31^{\mathrm{a} *}$ & $1.38 \pm 0.26^{\mathrm{b} *}$ & $1.88 \pm 0.26^{\mathrm{a} \#}$ & $1.69 \pm 0.22^{\mathrm{b}^{\wedge}}$ & $1.59 \pm 0.29^{\mathrm{b} *}$ \\
\hline Calcium (mg/g of kidney) & $3.14 \pm 0.34$ & $5.72 \pm 0.44^{a *}$ & $3.63 \pm 0.56^{\mathrm{b} *}$ & $4.27 \pm 0.78^{\mathrm{a}^{\wedge}, \mathrm{b} *}$ & $4.00 \pm 0.80^{\mathrm{b}^{\wedge}}$ & $3.85 \pm 0.26^{\mathrm{b} *}$ \\
\hline Oxalate (mg/g of kidney) & $1.03 \pm 0.26$ & $3.85 \pm 0.44^{a *}$ & $1.96 \pm 0.46^{\mathrm{a}^{\wedge} \mathrm{b} *}$ & $2.72 \pm 0.36^{\mathrm{a} *, \mathrm{~b} *}$ & $2.61 \pm 0.26^{\mathrm{a} * \mathrm{~b} *}$ & $2.10 \pm 0.71^{\mathrm{a}^{\wedge} \mathrm{b} *}$ \\
\hline MDA (nmol/mg of protein) & $0.58 \pm 0.13$ & $4.61 \pm 0.36^{\mathrm{a} *}$ & $1.45 \pm 0.43^{\mathrm{a}^{\wedge} \mathrm{b} *}$ & $3.23 \pm 0.72^{\mathrm{a} *, \mathrm{~b} *}$ & $2.65 \pm 0.37^{\mathrm{a} * \mathrm{~b} *}$ & $1.90 \pm 0.43^{\mathrm{a} * \mathrm{~b} * \mathrm{~s}}$ \\
\hline $\mathrm{SOD}(\mathrm{U} / \mathrm{min} / \mathrm{mg}$ of protein) & $6.05 \pm 0.61$ & $2.70 \pm 0.32^{a *}$ & $5.72 \pm 0.30^{\mathrm{b} *}$ & $3.68 \pm 0.51^{\mathrm{a} * \mathrm{~b}^{\wedge}}$ & $4.69 \pm 0.49^{a * b *}$ & $5.00 \pm 0.45^{\mathrm{a}^{\wedge} \mathrm{b} *}$ \\
\hline Catalase $\left(\mu \mathrm{M} / \mathrm{H}_{2} \mathrm{O}_{2} / \mathrm{min}\right)$ & $46.41 \pm 5.32$ & $20.83 \pm 3.44^{\mathrm{a} *}$ & $40.69 \pm 5.37^{\mathrm{b} *}$ & $30.48 \pm 2.69^{\mathrm{a} *, \mathrm{~b}^{\wedge}}$ & $31.86 \pm 4.97^{\mathrm{a} * \mathrm{~b} *}$ & $35.52 \pm 3.56^{\mathrm{a} * \mathrm{~b} *}$ \\
\hline $\mathrm{GSH}\left(\mu \mathrm{M} / \mathrm{H}_{2} \mathrm{O}_{2} / \mathrm{min}\right)$ & $9.58 \pm 1.41$ & $5.59 \pm 0.42^{a *}$ & $7.61 \pm 0.69^{\mathrm{a} * \mathrm{~b}, \mathrm{w}}$ & $6.29 \pm 0.54^{\mathrm{a} *}$ & $6.58 \pm 0.58^{\mathrm{a} *}$ & $7.02 \pm 0.47^{\mathrm{a} * \mathrm{~b} \#}$ \\
\hline
\end{tabular}

Values are expressed as mean \pm SD, 6 animals in each group. EG: Ethylene glycol, MDA: Malondialdehyde, GSH: Reduced glutathione, SOD: Superoxide dismutase.

Comparisons are made: ${ }^{a}$ with control, ${ }^{b}$ with model control (EG only). One way ANOVA followed by the Dunnett test. Symbols represent statistical significance: ${ }^{\#}<0.05$, $\wedge P<0.01, * P<0.001$.

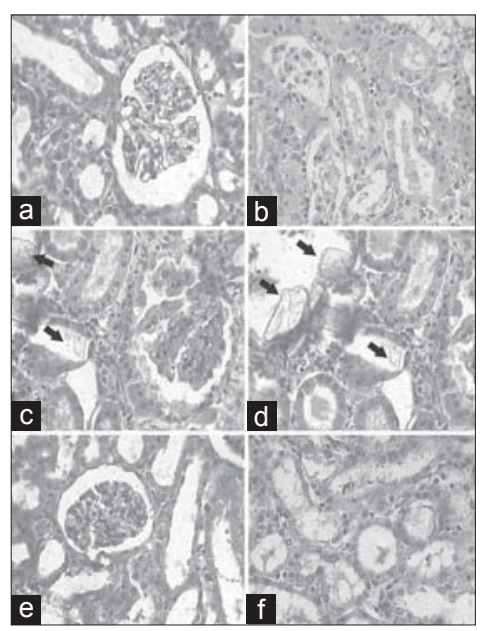

Figure 2: Light microscopic histology and $\mathrm{CaOX}$ deposits in the kidney section. Kidney section of $(a, b)$ vehicle control, $(c, d)$ urolithic and $(e, f)$ cystone treated $(750 \mathrm{mg} / \mathrm{kg})$. (a: glomeruli region and b: tubular region) (magnification $450 \times$ for all images)

the nucleation, which leads to inhibit crystal growth.

In this study, calcium and oxalate excretion are progressively increased in the calculi-induced animals. It has been reported that oxalates play an important role in stone formation and have about 15-fold greater effect than urinary calcium. The changes in the urinary oxalate level are relatively much more important than those of calcium. ${ }^{[33]}$ Elevated urinary calcium is a favoring factor for nucleation of $\mathrm{CaOX}$ from urine and further crystal growth. The reduction in calcium and oxalate excretion was observed on SXME treatment in a dose-dependent manner. This decreased excretion of oxalates may be due to the inhibition of formation of oxalates by the plant extract.

An increase in urinary phosphorus excretion was observed in the EG-induced urolithic rats. Increased excretion of phosphorous has been observed in stone formers. ${ }^{[34]}$ Elevated urinary phosphorus excretion along with oxalate stress seems to provide an environment appropriate for stone development by forming calcium phosphate

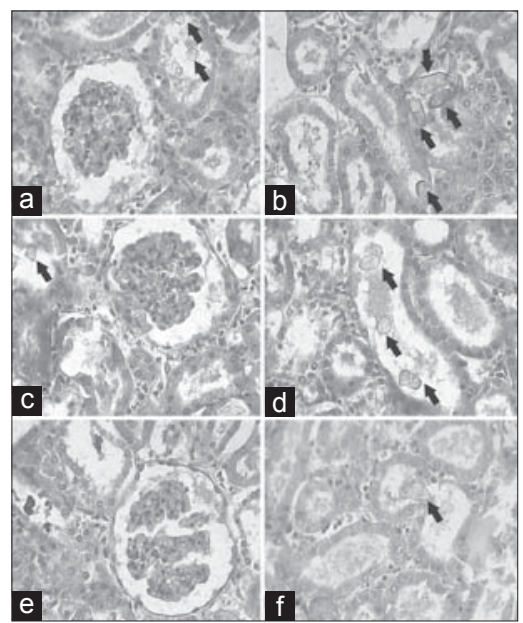

Figure 3: Light microscopic histology and CaOX deposits in the kidney section. Kidney section of Solanum xanthocarpum fruit extract treated (a, b) $100 \mathrm{mg} / \mathrm{kg}$, (c, d) $200 \mathrm{mg} / \mathrm{kg}$, and (e, f) $400 \mathrm{mg} / \mathrm{kg}$ (a: glomeruli region and b: tubular region) (magnification $450 \times$ for all images)

crystals, which epitaxially induces $\mathrm{CaOX}$ deposition. ${ }^{[19,33,34]}$ Treatment of SXME lowers excretion of phosphorus dose dependently and reduces the risk of stone formation.

Increased excretion of uric acid has been reported in stone formers and hyperoxaluric rats. Uric acid interferes with $\mathrm{CaOX}$ solubility, and it binds and reduces the inhibitory activity of glycosaminoglycans. ${ }^{[19]}$ The predominance of uric acid in $\mathrm{CaOX}$ stones, and the observation that uric acid binding proteins are capable of binding to $\mathrm{CaOX}$ and modulate its crystallization also suggests its primary role in stone formation. ${ }^{[3]}$ Drug treatment reduces uric acid levels near to normal thus decreasing the risk of stone formation.

Normal urine contains many inorganic and organic inhibitors of crystallization, magnesium and citrate are such well-known inhibitors. A low level of magnesium and citrate is also encountered in stone formers as well as in stone-forming rats. ${ }^{[20]}$ Promising results in preventing recurrence have been shown in patients treated with potassium magnesium citrate. Magnesium can reduce the 
supersaturation of $\mathrm{CaOX}$ by reducing the saturation of $\mathrm{CaOX}$. Magnesium has been found to decrease the growth and nucleation rates of $\mathrm{CaOX}$ crystals. ${ }^{[36]}$ Citrate is an important inhibitor of urolithiasis, which forms soluble complexes with calcium and inhibits precipitation of $\mathrm{CaOX}$ and phosphate, and growth of their crystals. ${ }^{[3]}$ Urinary magnesium and citrate were significantly diminished in the ethylene glycol-induced urolithic rats. The SXME treatment restored the magnesium and citrate excretion and thus reduces the growth of CaOX crystals in Groups IV-VI.

In urolithiasis, the glomerular filtration rate decreases due to the obstruction to the flow of urine by the stones in the urinary system. Due to this, the waste products, particularly nitrogenous substances such as urea, creatinine, BUN, and uric acid are accumulated in blood. ${ }^{[32]}$ In calculi-induced rats, marked renal damage was seen as indicated by the elevated serum levels of creatinine, urea, BUN, and uric acid that are markers of glomerular and tubular damage. Treatment with SXME showed to prevent the elevation of serum levels of these markers by improving glomerular filtration as it causes diuresis.

The development of tissue injury probably depends on the balance between the generation of reactive oxygen species (ROS) and the tissue antioxidant defense mechanism. Decreased tissue antioxidant enzymes may be followed to elevate free radical production in the early stages and in the later stages of nephrolithiasis, which may put the renal tissue under oxidative stress. This hypothesis is strengthened by the report that patients with kidney stones have less activity of antioxidant enzymes with increased lipid peroxidation. ${ }^{[38]}$ Oxidative damage as reflected from the increased level of markers of oxidative injury by higher MDA and decreased antioxidant enzymes activity such as SOD, catalase, and GSH level in the kidney as well as deteriorate since kidney functions as observed in calculiinduced rats. Treatment with SXME decreases the MDA level and increases the activity of antioxidant enzymes and the level of GSH indicates that it protected against oxidative stress induced tissue damage.

Microscopic examinations of kidney sections derived from ethylene-glycol-induced urolithic rats showed polymorphic irregular crystal deposits inside the tubules, which cause dilation of the proximal tubules along with interstitial inflammation and severe glomeruli damage with the hematuria indicated by RBCs deposition that might be attributed to oxalate. Co-treatment with the SXME decreased the number and size of $\mathrm{CaOX}$ deposits in different parts of the renal tissue and prevented damages caused due to EG. Moreover EG administration causes an inflammatory condition and deposition of crystalline components in the kidney which leads to increase the weight of kidney. Concurrent administration of SXME reduces the kidney weight by decreasing inflammation and increasing excretion of crystalline components.

The results showed the nephroprotective effects of S. xanthocarpum fruits in the ethylene-glycol-induced urolithiasis model. It is suggested that the effects could be by maintaining balance between stone promoters and inhibitors, reducing deposition and excretion of small particles of CaOX from the kidney, maintaining the antioxidant environment and reducing the chance of them being retained in the urinary tract. A number of herbal extracts and their isolated constituents have also shown protective effects against renal stone formation. ${ }^{[19,32]}$

Saponins, alkaloids, phytosterols, etc. are major phytoconsituents present in the $S$. xanthocarpum fruits. Saponin derivatives appeared as components of the great number of medicinal herbs with claimed antiurolithiatic properties. ${ }^{[39]}$ Phytosterols also had been antiinflammatory and antioxidant properties. ${ }^{[40]}$

\section{CONCLUSION}

The result indicates that administration of methanolic extract of $S$. xanthocarpum fruits to rats with the ethyleneglycol-induced urolithiasis reduced and prevented the growth of urinary stones by diuresis, antioxidant activity and maintaining balance between stone promoters and inhibitors constituents. This study supporting folklore information regarding the antiurolithiatic activity of $S$. xanthocarpum.

\section{ACKNOWLEDGMENT}

The authors are thankful to Dr. Samir Patel, (M.D. Patho.), Samarth Pathology Lab., Surat, India, for providing facilities for biochemicals analysis and histopathology.

\section{REFERENCES}

1. Mukharjee T, Bhalla N, Aulakh GS, Jain HC. Herbal drugs for urinary stones - literature appraisal. Indian Drugs 1984;21:224-8.

2. The Wealth of India, Raw materials. Vol. 9. Rh-So. New Delhi: Council of Scientific and Industrial Research; 1989. p. 393-4.

3. Indian Herbal Pharmacopoeia. $1^{\text {st }}$ ed., vol. 2. India: A joint publication of Regional research lab, Jammu Tawi and Indian Drug Manufacturers' Association; 1998.

4. Kiritikar KR, Basu BD. Indian Medicinal Plants. $2^{\text {nd }}$ ed., vol. 3. Dehradun: International Book Distributors; 1994.

5. Sivarajan VV, Balachandran I. Ayurvedic drugs and their plant sources. New Delhi: Oxford and IBH Publishing Co. Pvt. Ltd; 2004. 
6. Chopra RN, Nayar SL, Chopra IC. Glossary of Indian Medicinal Plants. New Delhi: Council of Scientific and Industrial Research; 1956.

7. Jain SP, Puri HS. Ethnomedicinal plants of Jaunsar-Bawar Hills, Uttar Pradesh, India. J Ethnopharmacol 1984;12:213-22.

8. Chauhan PN, Kuamr D, Kasana MS. Medicinal plants of Muzaffarnagar district used in treatment of urinary track and kidney stone. Indian J Tradit Know 2009;8:191-5.

9. Gogte VM. Ayurvedic pharmacology and therpeutic uses of medicinal plants (Dravyagunavignyan). Swami Prakashananda Ayurveda Research Centre, Mumbai: Bhartiya Vidya Bahvan; 2000. p. 327-9.

10. Sharma PC, Yelne MB, Dennis TJ. Database of medicinal plants used in used in Ayurveda. New Delhi: Central Council of Research in Ayurveda and Siddha; 2000.

11. The Ayurvedic Pharmacopoeia of Indian. $1^{\text {st }}$ ed., Part 1, Vol. 1. New Delhi: Ministry of Health and Family Welfare; 2001. p. 59-61.

12. Kar DM, Maharana L, Pattnaik S, Dash GK. Studies on hypoglycaemic activity of solanum xanthocarpum schrad. and wendl. fruit extract in rats. J Ethnopharmacol 2006;108:251-6.

13. Singh MP, Panda H. Medicinal herbs with their formulations. Vol. 2. Delhi: Daya Publishing House; 2005.

14. Gupta SS, Rai M, Gupta NK. Histamine releasing effects of a few Indian medicinal plants used in bronchial asthma. Curr Sci 1967;36:42-3.

15. Dhar ML, Dhar MM, Dhawan BN, Mehrotra BN, Ray C. Screening of Indian plants for biological activity. Part I. Indian J Exp Biol 1968;6:232-47.

16. United States Pharmacopoeia 30. Chapter 467: Residual solvents, 2007.

17. Tandon PN, Mahajan RC, Anand N, Basu SK, Ganguly NK, Kamboj VP, et al. Guideline for the care and use of animals in scientific research, Revised edition. Indian National Science Academy, New Delhi; 2000.

18. Handa SS, Anupama S. Hepatoprotective activity of andrographolide from Andrographis paniculate against $\mathrm{CCl}_{4}$. Indian J Med Res 1990;92:276.

19. Selvam R, Kalaiselvi P, Govindaraj A, Murugan VB, Kumar AS. Effect of A. lanatai leaf extract and Vediuppu Chunnam on the urinary risk factors of calcium oxalate urolithiasis during experimental Hyperoxaluria. Pharmacol Res 2001;43:89-93.

20. Shukkur MF, Abdul SE, Devarajan A, Ramasamy S, Sethumadhvan S, Nachiappa GR, et al. Credential of Spiruina diet on stability and flux related properties on the biomineralization process during oxalate mediated renal calcification in rats. Clin Nutr 2005;24:932-42.

21. Lorentz K. Improve determination of calcium with ortho-cresolphthalein complexone. Clin Chim Acta 1982;126:327-33.

22. Hodgkinson A. Determination of oxalic acid in biological material. Clin Chem 1970;16:547-57.

23. Heaton FW. Determination of magnesium by the titan yellow and ammonium phosphate method. J Clin Pathol 1960;13:358-60.
24. Fiske $\mathrm{CH}$, Subbarow Y. The colorimetric determination of phosphorus. J Biol Chem 1925;66:375-81.

25. Verley H. Practical Clinical Biochemistry. New Delhi: CBS Publishers; 2003.

26. Rajagopal G. A simple colorimetric procedure for estimation of citric acid in urine. Indian J Exp Biol 1984;22:391-2.

27. Parasuraman S, Raveendran R, Kesavan R. Blood sample collection in small laboratory animals. J Pharmacol Pharmacother 2010;1:87-93.

28. Anand R, Patanaik GK, Roy K, Bhaduri AP. Antioxaluric and anticalciuric activity of lupeol derivatives. Indian J Pharmacol 1995;27:265-9.

29. Malini MM, Baskar R, Varalakshmi P. Effect of lupeol, a pentacyclic triterpene on urinary enzyme in hyperoxaluric rats. Jpn J Med Sci Biol 1995;48:211-20.

30. Huang HS, Chen J, Chen CF. Circulating adhesion molecules and neutral endopeptidase enzymuria in patients with urolithiasis and hydronephrosis. Urology 2000;55:961-5.

31. Khan SR, Finlayson B, Hackett RL. Experimental calcium oxalate nephrolithiasis in rat: Role of the renal papilla. Am J Pathol 1982;107:59-69.

32. Atmani F, Slimani Y, Mimouni M, Hachtm B. Prophylaxis of calcium oxalate stones by Herniaria birsute on experimentally induced nephrolithiasis in rats. BJU Int 2003;92:137-40.

33. Karadi RV, Gadge N, Alagawadi KR, Savadi RV. Effect of Moringa oleifera Lam. root-wood on ethylene glycol induced urolithiasis in rats. J Ethnopharmacol 2006;105:306-11.

34. Soundarajan P, Mahesh R, Ramesh T, Begum VH. Effect of Aerva lanata on calcium oxalate urolithiasis in rats. Indian J Exp Biol 2006;44:981-6.

35. Kalaiselvi P, Udayapriya KL, Selvam R. Uric acid binding proteins in calcium oxalate crystallization. BJU Int 1999;83:919-23.

36. Grases F, Genestar C, Conte A, March P, Costa-Bauza A. Inhibitory effect of pyrophosphate, citrate, magnesium and chondroitin sulfate in calcium oxalate urolithiasis. Br J Urol 1989;64:235-7.

37. Francois B, Cahen R, Pascal B. Inhibitors of urinary stone formation in 40 recurrent stone formers. Br J Urol 1986;58:479-83.

38. Huang HS, Ma MC, Chen J, Chen CF. Changes in the oxidant-antioxidant balance in the kidney of rats with nephrolithiasis induced by ethylene glycol. J Urol 2002;167:2584-93.

39. Lakhsminarasimhan V, Mahimainathan L, Palaninathan V. Evaluation of the effect of triterpenes on urinary risk factors of stone formation in pyridoxine deficient hyperoxiluric rats. Phytother Res 2002;16:514-8.

40. Dreikorn K. Complementary and alternative medicine in urology. BJU Int 2005;96:1177-84.

How to cite this article: Patel PK, Patel MA, Saralai MG, Gandhi TR. Antiurolithiatic effects of Solanum xanthocarpum fruit extract on ethyleneglycol-induced nephrolithiasis in rats. J Young Pharmacists 2012;4:164-70.

Source of Support: Nil, Conflict of Interest: None declared.

\section{Author Help: Reference checking facility}

The manuscript system (www.journalonweb.com) allows the authors to check and verify the accuracy and style of references. The tool checks the references with PubMed as per a predefined style. Authors are encouraged to use this facility, before submitting articles to the journal.

- The style as well as bibliographic elements should be $100 \%$ accurate, to help get the references verified from the system. Even a single spelling error or addition of issue number/month of publication will lead to an error when verifying the reference.

- $\quad$ Example of a correct style

Sheahan P, O'leary G, Lee G, Fitzgibbon J. Cystic cervical metastases: Incidence and diagnosis using fine needle aspiration biopsy. Otolaryngol Head Neck Surg 2002;127:294-8.

- $\quad$ Only the references from journals indexed in PubMed will be checked.

- $\quad$ Enter each reference in new line, without a serial number.

- $\quad$ Add up to a maximum of 15 references at a time.

- If the reference is correct for its bibliographic elements and punctuations, it will be shown as CORRECT and a link to the correct article in PubMed will be given.

- If any of the bibliographic elements are missing, incorrect or extra (such as issue number), it will be shown as INCORRECT and link to possible articles in PubMed will be given. 